\title{
Changes in medicine consumption of omalizumab after transition to home self-administration
}

Sofie Jepsen ${ }^{1}$ and Tina Skjold ${ }^{2}$

${ }^{1}$ Aarhus Universitet

${ }^{2}$ Aarhus Universitetshospital

September 28, 2021

\section{Hosted file}

Letters to the Editor.docx available at https://authorea.com/users/438391/articles/ 539596-changes-in-medicine-consumption-of-omalizumab-after-transition-to-home-selfadministration

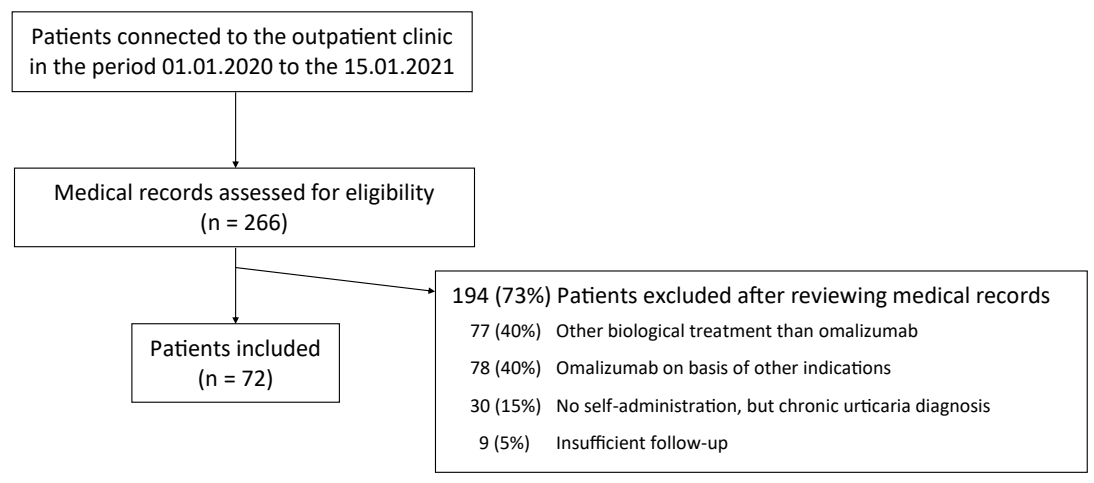

